\author{
Harriet C. Thoeny \\ Frederik De Keyzer
}

\section{Extracranial applications of diffusion-weighted magnetic resonance imaging}

Received: 24 May 2006

Revised: 3 November 2006

Accepted: 28 November 2006

Published online: 6 January 2007

(C) Springer-Verlag 2007

H. C. Thoeny $(\bowtie)$

Department of Radiology,

Neuroradiology and Nuclear Medicine,

University Hospital of Bern,

Inselspital, Freiburgstrasse 10,

CH-3010 Bern, Switzerland

e-mail: Harriet.Thoeny@insel.ch

Tel.: +41-31-6322111

Fax: +41-31-6324874

F. De Keyzer

Department of Radiology,

University Hospitals Leuven,

3000 Leuven, Belgium

\begin{abstract}
Diffusion-weighted MRI
has become more and more popular in the last couple of years. It is already an accepted diagnostic tool for patients with acute stroke, but is more difficult to use for extracranial applications due to technical challenges mostly related to motion sensitivity and susceptibility variations (e.g., respiration and air-tissue boundaries). However, thanks to the newer technical developments, applications of body DWMRI are starting to emerge. In this review, we aim to provide an overview of the current status of the published data on DW-MRI in extracranial applications. A short introduction to
\end{abstract}

the physical background of this promising technique is provided, followed by the current status, subdivided into three main topics, the functional evaluation, tissue characterization and therapy monitoring.

Keywords Diffusion-weighted MRI · Functional evaluation - Magnetic resonance imaging - Therapy monitoring $\cdot$ Tissue characterization

\section{Introduction}

The theory of measuring self-diffusion, which is the Brownian motion of the water molecules in the tissues, by means of magnetic resonance imaging (MRI) was already introduced by Carr and Purcell in 1954 [1]. Their ideas were based on an article by Hahn et al. in which the influence of self-diffusion on the measured signal was described [2]. Carr and Purcell adapted the Hahn-echo imaging scheme in order to obtain diffusion-insensitive T2 measurements of tissues and subsequently to quantify the amount of self-diffusion in tissues. With the introduction of a pulsed gradient spin-echo scheme by Stejskal and Tanner in the late 1960s, the applicability of diffusion-weighted (DW) nuclear MR was largely increased [3]. Their applied gradient scheme allowed easier and more robust measurements and enabled better definition of the actual diffusion time allowed for proton movement in the tissues. Almost all of the currently used diffusion measurements are based on the Stejskal-Tanner gradient scheme.
Unfortunately, diffusion-weighted imaging suffers from a number of technical challenges. As the diffusion weighting needs to be repeated a large number of times to allow accurate assessment of the diffusion of water molecules, ultrafast imaging sequences are invaluable. However, these ultrafast sequences are usually single-shot, meaning they have a long echo train length (ETL). A long ETL makes the sequences highly dependent on the effects of tissue homogeneity and air-tissue boundaries (especially in gradient-echo-based sequences). These dependencies introduce a number of artifacts in the resulting images.

Due to the low incidence of movement artifacts and the very high brain homogeneity and high signal-to-noise ratio (SNR), most early research on DW-MRI was performed in the brain. The first important clinical application was reported in 1990, when Moseley et al. found that diffusion imaging in a cat brain allowed the detection of ischemic brain areas in the first $30 \mathrm{~min}$ after onset [4].

At about the same time, Le Bihan et al. suggested that the brain perfusion could be viewed as a pseudo-diffusion 
process and could be approximated using the intravoxel incoherent motion technique [5]. Later on, it was shown that the incoherent motion was not only caused by a combination of intra- and extracellular water molecules and blood perfusion, but also had contributions from tubular flow and intercellular hindrances to proton mobility, such as fibrosis [6].

Clinically, DW-MR imaging is now an established method used routinely at many institutions for the diagnosis of acute stroke [7]. Over the last few years, DW-MRI has become increasingly used in extracranial organs. DWMRI of abdominal organs, for instance, is much more difficult to perform due to physiological motion artifacts (bowel, cardiac and respiratory motions) and the heterogeneous composition of the organs [8]. However, thanks to faster imaging techniques, DW-MRI has been increasingly applied for the functional evaluation of different organs such as the kidneys and the salivary glands, to characterize lesions, to monitor different treatment options and to predict the outcome of therapy. In this article we outline the biological basis of DW-MRI observations as well as review extracranial applications of DW-MRI in assessing organ functionality and for tissue characterization as well as consider the potential of this method to monitor tumor treatment and predict patient outcomes.

\section{Basics of DW-MRI}

In order to make an MRI sequence sensitive to the diffusion of water molecules, the sequence is expanded with a diffusion-sensitizing gradient scheme. Currently, the most commonly used DW-MRI sequence is a combination of a Stejskal-Tanner diffusion-sensitizing gradient scheme, followed by a very fast, single-shot gradient-echo data collection sequence (echoplanar imaging, EPI).

The Stejskal-Tanner scheme is based on the use of two equal-sized gradients, separated by a 180 degree radiofrequency (RF) pulse (Fig. 1).

The different effect of these two gradients on stationary and moving water molecules is explained in the following figure (Fig. 2). Stationary molecules (such as cubes 1 and 2) start off in phase with each other after the $90^{\circ} \mathrm{RF}$ pulse. The first gradient induces a faster rotation in the molecules that are more to the right of the image and a slower one on the left side, as indicated in the image. The $180^{\circ} \mathrm{RF}$ pulse then rotates the vectors around the vertical axis. If the molecules have not moved substantially between the first and second gradient, the extra rotation induced by the second gradient will be identical to the first one, and all stationary molecules will be in phase at the end of the second gradient. If cube 3 is on position $\mathrm{x} 1$ during the first gradient, but on position $\mathrm{x} 2$ during the second gradient, the second extra rotation will no longer be identical to the first, and the molecule will be out of phase.

An out-of-phase situation will yield a lower signal than an in-phase configuration; therefore, the greater the movement, the lower the signal measured will be. Also, the higher the gradient strength $\mathrm{G}$ applied, the stronger this signal loss will be. The amount of diffusion-sensitizing applied is usually indicated by the b-value, which is given by (see also the image above for a definition of the symbols used):

$b=\gamma^{2 *} G^{2 *} \delta^{2 *}\left(\Delta-\frac{\delta}{3}\right)$

where $\gamma$ is the gyromagnetic ratio, $G$ the strength of the gradient used, $\delta$ the duration of the gradient and $\Delta$ the time between the two gradients.

This signal loss as a function of the b-value (or diffusion weighting) usually shows an exponential behavior (Fig. 3). Quantification of the DW-MRI images is performed by calculating the apparent diffusion coefficient (ADC) from the generic formula for this decreasing exponential behavior:

$$
S_{i}=S_{0}^{*} e^{-b_{i}^{*} A D C}
$$

Fig. 1 Stejskal-Tanner gradient scheme for diffusion-sensitization of the tissue signal

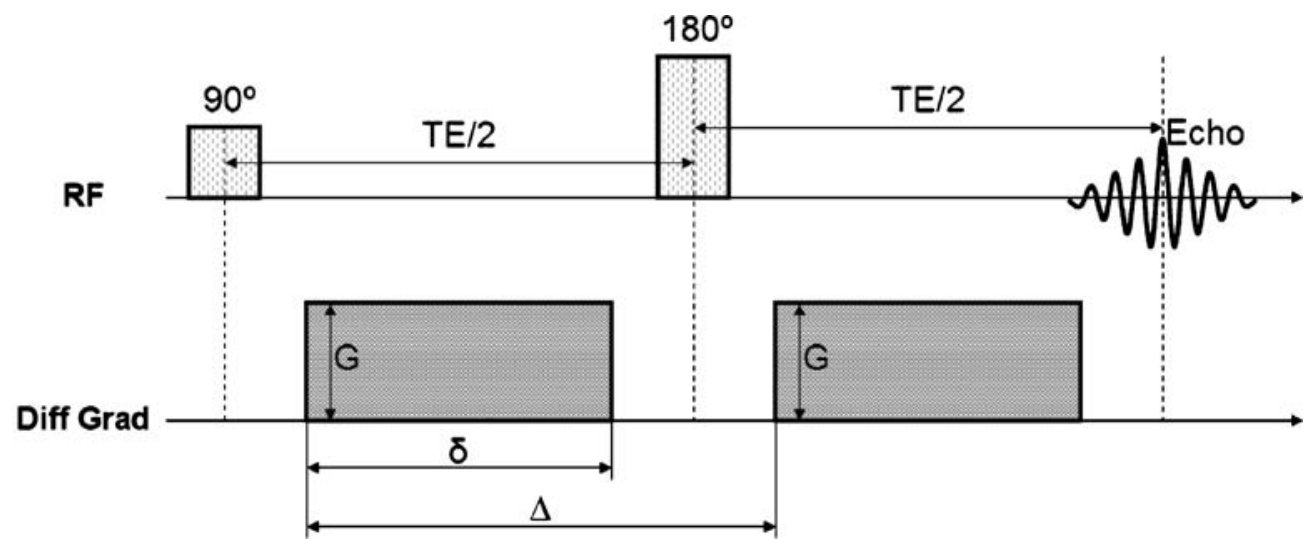


Fig. 2 Non-uniform effect induced in stationary and moving spins by the diffusion-sensitizing gradients
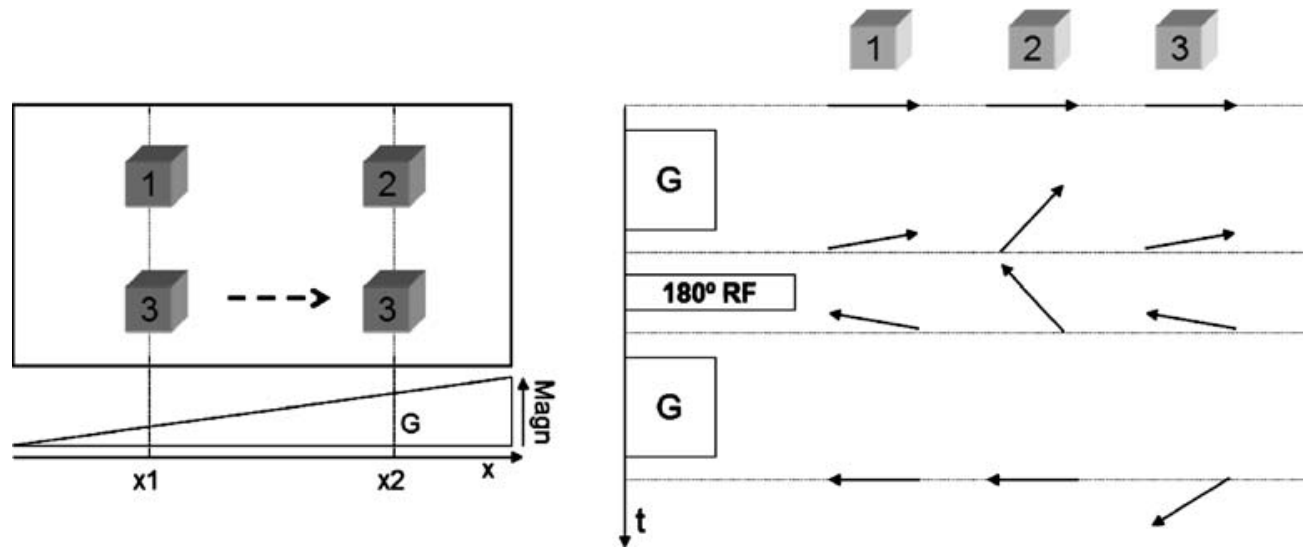

with $\mathrm{S}_{\mathrm{i}}$ the signal intensity measured using a $b$-value $b_{i}$ and $S_{0}$ the signal intensity for $b=0 \mathrm{~s} / \mathrm{mm}^{2}$.

A major advantage of calculating $\mathrm{ADC}$ values is that these values are independent of the position of the imaged tissue in the receiver coils. However, all moving molecules induce a signal loss and therefore contribute to the ADC
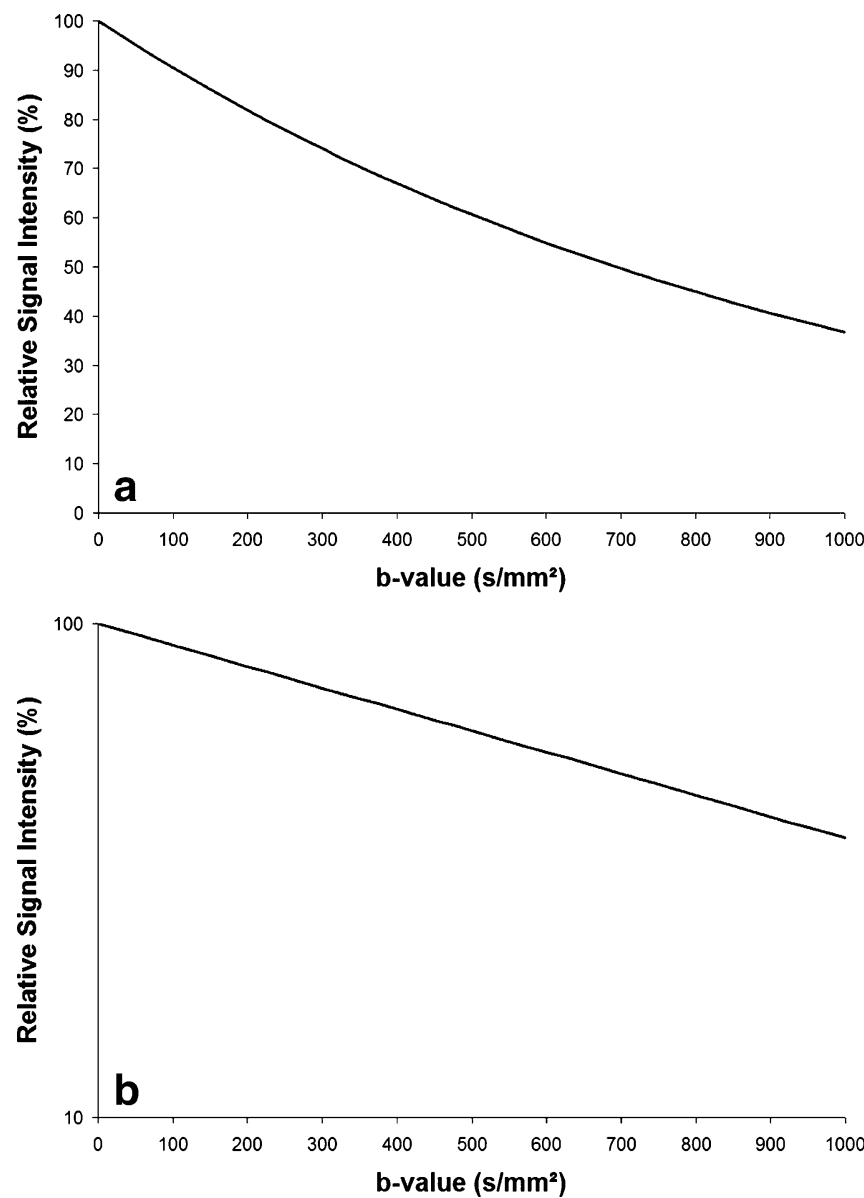

Fig. 3 Example of the relative signal intensity decrease with increasing b-value on a (a) linear and (b) logarithmic scale. The curve in the graphs represents a tissue with an apparent diffusion coefficient of $0.001 \mathrm{~mm}^{2} / \mathrm{s}$ value. This means that the diffusion in the extracellularextravascular space, cellular diffusion and intravascular perfusion all contribute to the calculated ADC value. Thus, DW-MRI provides information on perfusion and diffusion simultaneously in any organ. It has been shown that the choice of b-values plays an important role in which of these contributions has the most influence [5,9]. The effect of the movement on the ADC value is inversely related to the speed of movement of the water molecules. Using low b-values (typically up to 200 or $300 \mathrm{~s} / \mathrm{mm}^{2}$ ), the fastest moving spins have the strongest effect. The origin of these fast spins is still under debate, but can most likely be attributed to perfusion effects and guided movement of extravascular extracellular water molecules [9]. In higher b-values, the fastest moving spins have already lost their signal; therefore, the effect of the slower movements such as the Brownian displacement of extra- and intracellular molecules and transmembraneous transport can be assessed [10].

Whenever the micro-architecture of a tissue is changed, either with respect to the blood vessel density, the addition or removal of structural inhibitors or most importantly by the different ratio of extracellular extravascular space over the intracellular space, this can be detected using DW-MRI, provided an optimal choice of b-values is selected. The $\mathrm{ADC}$ is reported to be related to the cellular density of a tumor, for instance, and reduced ADC has been observed in most types of malignant tumors due to the consequent decrease of the extracellular extravascular space [11].

The second very important part of a diffusion-weighted acquisition is the underlying imaging sequence used. In theory, any imaging sequence can be adapted with bipolar gradients to allow the assessment of water molecule diffusion. However, due to time constrictions, predominantly single-shot sequences are used nowadays. The fastest and most often used technique, EPI, is a gradientecho-based technique and therefore has the inherent problems with susceptibility, especially when many airtissue boundaries are present. Also, movement artifacts tend to have a stronger effect in gradient-echo acquisitions. As both factors are more pronounced in extracranial 
applications, some researchers tend to use alternative acquisition schemes such as single-shot turbo-spin-echo, steady-state free precession, multi-shot EPI and line scan diffusion-weighted imaging. A comprehensive comparison of these techniques is beyond the scope of the current manuscript, but more information can be found in the literature [12, and references therein].

\section{Functional evaluation}

As mentioned above, the mechanism of DW-MRI is based on the movement of water molecules in tissue and more importantly on the hindrances/facilitations of these water molecule movements. From this idea, DW-MRI would seem an ideal tool to examine the function of tissues that are based on production, displacement or excretion of fluid. The first uses of DW-MRI for the functional evaluation of tissues were in the kidneys, as these have a high amount of tubular perfusion and diffusion to allow for water and waste product excretion. More recently, functional evaluation by DW-MRI has spread to other organs that specialize in fluid production and transport such as the salivary glands and pancreas. Below, we consider how DW-MRI has been used for the functional evaluation of each of these organs.

Several reports dealing with diffusion-weighted MRI of the kidneys have been published. However, most of these have been preliminary and performed in healthy volunteers investigating the feasibility of DW-MRI and addressing technical aspects [13-16]. For example, in healthy children, an age-dependence of the ADC could be observed with the greatest changes during the first years of life [17]. There has been an ongoing controversy about whether ADC values are higher in the renal cortex or medulla. While several papers found higher ADC values in the medulla than in the cortex $[14,18,19]$, more recent papers including our own work found just the opposite [13, 20 $22]$. Very different $A D C$ values have been reported for control kidneys ranging from $1.63 \times 10^{-3} \mathrm{~mm}^{2} / \mathrm{s}$ [8] to $5.76 \times 10^{-3} \mathrm{~mm}^{2} / \mathrm{s}$ [23]. These differences are primarily due to the selected $b$-value ranges and hamper comparisons between studies.

In experimental settings, DW-MRI has been applied in the evaluation of renal artery stenosis (RAS) and ureteral obstruction in pigs [24], showing a decrease of the ADC in both pathologies, with diuresis having no meaningful effect. In another study on pigs, DW-MRI was able to differentiate acute and chronic ureteral obstruction [25]. Diabetic rats with cellular edema showed significantly lower ADC values in the kidneys than the control group; the results correlated with histopathological findings [26]. A decrease in ADC in dog kidneys following ischemia induced by renal artery ligation has been described [27].

In patients with acute and chronic renal failure, ADC values in the cortex and medulla were significantly lower than those of the normal kidneys with ADC values being lowest for patients with chronic renal failure $[19,22]$. Also, in patients with RAS the ADC values in the cortex, but not in the medulla, were significantly lower than those of normal and contralateral kidneys. Furthermore, a linear correlation between renal ADC values and serum creatinine levels was observed [28]. DW-MRI may be applied for the differentiation of pyonephrosis from hydronephrosis [29]. Another study [30] showed that ADC values in hydronephrosis were reduced only if it was accompanied by renal dysfunction. A positive correlation was observed between $\mathrm{ADC}$ values and the split glomerular filtration rate (GFR). In renal tumors different ADC values were observed when compared to the normal renal parenchyma [31].

In transplanted kidneys, DW-MRI has only been performed in an animal study. In this experimental transplant rejection model, ADC values in the cortex and medulla decreased significantly, suggesting the potential of this method for monitoring early graft rejection [21].

There are few reports on the use of DW-MRI for assessing salivary gland function and tissue characterization [32-35].

Decreased salivary function is an important component of various pathological conditions and is itself associated with many additional disorders. For example, salivary gland dysfunction has an important clinical impact in patients undergoing radiotherapy for head and neck cancer.

It was demonstrated that decreased salivary gland ADC values correlated significantly with decreased salivary function determined scintigraphically in patients after radiotherapy [34]. However, the correlation between DWMRI and scintigraphic values was small. This may be due to the fact that DW-MRI was performed at rest, whereas scintigraphy was performed during gustatory stimulation [34]. Employing DW-MRI in unstimulated salivary glands does not reflect maximal saliva production. Therefore, in two other studies DW-MRI was performed during gustatory stimulation and was able to detect changes in ADC of the salivary glands during stimulation $[35,36]$.

In patients with Sjögren's syndrome, the ADC correlated with the salivary flow rates. The ADC was increased in patients with sialadenitis and decreased with abscess formation [32].

Considerable discrepancies among ADC values of the salivary glands in healthy volunteers are found in published reports [32-34]. It has been shown that by varying the contribution of molecular diffusion, tissue perfusion and saliva flow, the ADC values are influenced by the chosen b-values [9]. Therefore, attention has to be paid when interpreting different studies.

In a recent study investigating parotid gland tumors of 45 patients, DW-MRI was reported to be able to differentiate benign from malignant primary tumors by means of the measured ADC values [37]. However, a differentiation among the various histological types was not possible. 
In a recent study, DW-MRI of the pancreas was applied before and after secretin administration in patients with chronic pancreatitis in a risk group for chronic pancreatitis and in healthy volunteers. The control subjects showed a median peak increase in ADC of $75 \%$ after a median time of $2 \mathrm{~min}$ after secretin administration, whereas in the patients with chronic pancreatitis no ADC peak was observed within $10 \mathrm{~min}$ after secretin administration. These findings provide clinically relevant information for detecting functional alterations in patients with chronic pancreatitis [38].

\section{Tissue characterization}

One of the main problems in daily clinical practice is the differentiation between benign and malignant lesions in various organs that DW-MRI can address. The advantages of DW-MRI in this aspect are entire tumor coverage and safety in the assessment performed. In contradistinction, tissue sampling is invasive and may not be representative of the entire tumor and also carries the inherent risks of infection, hemorrhage and seeding along the needle tract [39]. It has been repeatedly noted that ADC is related to the cellular density of tumors [11, 40-42]. Reduced ADC values have been reported for most malignant tumors $[16$, $43,44]$ and are thought to be due to cellular membranes impeding the mobility of water protons $[11,41]$. Necrotic tissues, on the other hand, show high ADC values resulting from larger diffusion distances as a consequence of lost membrane integrity [11]. It is because of the high sensitivity of DW-MRI to molecular displacements (in the orders of microns; three orders of magnitude less than the spatial resolution of a typical clinical MRI scan) that this method is very sensitive to biophysical changes related to pathologies, even during their very early stages of development [45].

ADC measurements for the evaluation of hepatic fibrosis showed decreased values as the stage of liver disease progressed or as the Child-Pugh stage progressed [46]. This is an important finding that might help to reduce the number of liver biopsies to assess the stage of disease in patients with hepatic fibrosis. For example, in a prospective study in 66 patients, DW-MRI was able to differentiate between benign and malignant focal hepatic lesions, with $\mathrm{ADC}$ of benign lesions being significantly higher than the ADC of malignant lesions [47]. Metastatic lesions and hepatocellular carcinomas had the lowest ADC, probably due to their high cellularity, restricting water diffusion. All malignant lesions included in this study were solid and did not have cystic components that might have increased the ADC. An interesting study published recently showed in a small number of patients $(n=6)$ that detection of malignant lesions of the liver using DW-MRI was improved after contrast enhancement with superparamagnetic iron oxide thanks to the improved contrast-to-noise ratio between malignant lesions and normal liver compared to conventional MRI and DW-MRI alone [48].

In line with these findings is the reduced ADC of malignant breast tumors compared to that of benign lesions and normal tissue noted in 23 patients. This difference was related to the increased cellularity of malignant lesions [49]. Guo et al. also showed a statistical difference of ADC value between malignant and benign breast lesions; the sensitivity was $93 \%$ and specificity was $88 \%$ with an ADC threshold of $1.30 \times 10^{-3} \mathrm{~mm}^{2} / \mathrm{s}$ [50]. Similar results were observed in a study performed on 76 patients with breast carcinoma with a $95 \%$ sensitivity for malignant tumors using a threshold of less than $1.6 \times 10^{-3} \mathrm{~mm}^{2} / \mathrm{s}$ [51].

In contrast to this study, metastatic cervical lymph nodes in patients with head and neck cancer had a significantly higher ADC than those with benign nodes. An explanation for this discrepancy might be that squamous cell carcinomas tend to be partially necrotic and therefore to have a higher ADC. In nodal lymphomas, however, the ADC was significantly lower than in benign nodes in the same study, apparently due to higher cellular density [52]. Furthermore, the ADC of metastatic nodes from highly or moderately differentiated cancers was significantly greater than that from poorly differentiated cancers. This is an interesting issue; however, histo-pathological correlations are required for further evaluation.

The accurate detection of recurrent or residual cholesteatoma is challenging because differentiation from granulation or fibrous tissue, which are common after surgery, is often very difficult to discern by CT or conventional MRI. Recently, several articles have shown the potential of DWMRI to depict recurrent or residual cholesteatoma in patients who have undergone middle ear surgery [53-57].

It has been shown that vertebral metastases can also be distinguished from normal vertebrae by their significantly lower ADC values [58]. However, in daily practice the differentiation between benign and malignant compression fractures is a more important problem than the diagnosis of vertebral metastases only. Therefore, the majority of the articles published deal with this problem. In these articles, it has been noted that metastatic compression fractures have a lower ADC compared to benign, osteoporotic compression fractures; therefore, the DW-MRI method offers the potential for characterization of acute vertebral compression fractures, which can be problematic in clinical practice $[58,59]$. Even qualitative analysis of DW-MRI has been shown to be able to distinguish between benign and malignant vertebral compression fractures $[60,61]$. Benign osteoporotic fractures were hypointense compared to the surrounding normal bone marrow on DW-MRI, whereas in malignant vertebral compression fractures, the signal intensity was increased compared to that of normal bone marrow [62]. These findings were confirmed in another investigation [61]. In this study the ADC values were also analyzed and were shown to be higher in benign compared to malignant compression fractures. Qualitative analysis 
after radiotherapy of metastatic disease of the spine evidenced a change from hyperintense signal before therapy to hypointense relative to normal vertebral bodies after therapy [63]. These findings suggest the potential of DW-MRI to monitor the treatment response of successful radiation therapy.

A study performed on 23 histologically proven soft tissue tumors showed the ability of DW-MRI to differentiate between benign and malignant lesions with true diffusion coefficients of malignant tumors being significantly lower than those of benign masses [64]. In contrast to these findings, the ADC values of benign soft tissue tumors overlapped with non-treated sarcomas, whereas the ADC values increased in all radiated sarcomas, suggesting the DW-MRI as a potential tool for evaluating treatment response [65]. In contrast to the study of Rijswijk et al. where true diffusion coefficients and perfusion fractions were separated, in the study of Einarsdottir et al. only the ADC values of two b-factors $\left(0\right.$ and $\left.600 \mathrm{~s} / \mathrm{mm}^{2}\right)$ were calculated, a potential explanation for this discrepancy.

Overall, the use of DW-MRI in discriminating between benign and malignant ovarian tumors has been disappointing due to prominent cystic components in this pathology [66]. However, in another study performed on 131 patients with cystic ovarian masses, the ADC was helpful in the differential diagnosis of mature cystic teratomas with a small amount of fat. The difference in ADC between benign and malignant lesions was only significant when mature cystic teratomas and endometrial cysts were included, but was not significant when they were excluded [67].

DW-MRI applied in addition to conventional T2W imaging has been found to improve the detection of prostate cancer [68]. In another study performed on a small group of patients $(n=10)$ with prostate cancer using an endorectal coil, the mean ADC value of malignant tumors in the peripheral zone was lower than that of non-malignant glandular tissues with an overlap between individual values [69]. In a recently published study performed on a 3-T MR unit on 49 patients, the ADC values were lower for tumors compared to the normal-appearing peripheral zone; however, a considerable intersubject variability was observed [70].

\section{Monitoring of treatment response}

The prediction and detection of the therapeutic response as well as characterization of residual disease are of utmost importance in cancer imaging. DW-MRI has been used as a way of assessing tumor response during follow-up with various treatment modalities (e.g., chemotherapy and radiation therapy) [71-75]. In these settings, DW-MRI has a number of advantages over other imaging techniques (e.g., CT and PET). DW-MRI is noninvasive, requires no ionizing radiation exposure and does not require the administration of contrast medium. The short examination time, especially when using parallel imaging, is an additional advantage, as is the ability to assess the tumor completely. In addition, parallel imaging offers the benefit of reduced artifacts, which becomes very important in DW-MRI. The early detection of non-responders or even prediction of response to treatment would allow changes of therapy in order to minimize treatment-related toxicity. Furthermore, both conventional morphologic and physiologic assessments can be made during the same examination.

Pre-therapy ADC maps can indicate the eventual outcome of therapy. An initial and transient decrease in ADC following therapy may be observed, probably representing pre-apoptotic cellular swelling. An increase in ADC thereafter due to the onset of apoptosis and present necrosis corresponds to successful therapy. The change in ADC following treatment may predict the outcome of therapy. A decrease in ADC later on, however, raises the suspicion of tumor recurrence [73].

The ability to predict therapy outcome has been shown by a preliminary study in 14 patients with locally advanced rectal cancer, where a strong negative correlation was found between mean pre-treatment tumor ADC and the percentage size change of tumors after chemotherapy and chemoradiation [71]. In an experimental setting, DW-MRI has been used for monitoring the effect of a vascular targeting agent, Combretastatin A-4 phosphate (CA4P), on rhabdomyosarcomas in rats [73]. DW-MRI allowed noninvasive detection and quantification of antivascular effects and as well provided information on the differentiation between the remaining viable and treated necrotic tumor tissues. Furthermore, when DW-MRI was applied for in vivo monitoring of repeated administrations of CA4P, the pre-treatment ADC values correlated with the outcome after CA4P administration; this study emphasized the potential of DW-MRI as a predictive biomarker for treatment outcome. In another experimental study again looking at CA4P effects, a good correlation between perfusion-associated $\mathrm{ADC}$ values and perfusion parameters from dynamic contrast-enhanced MRI (DCE-MRI) were found. While DCE-MRI was more sensitive to smaller vascular changes, only the ADC of high b-values allowed differentiation between viable and necrotic tumor tissue [76].

Further evidence of the ability of DW-MRI to monitor therapy effects comes from studies of ablated tissues after focused ultrasound treatment of uterine fibroids. The ADC values for treated fibroids were significantly higher than the ADC values of untreated fibroid tissue in a prospective study on 14 patients [77]. Similar results have been obtained in a small group of patients $(n=8)$ undergoing transarterial chemoembolization of large hepatocellular carcinomas, where DW-MRI was able to predict the degree of tumor necrosis [78]. 


\section{Conclusion}

DW-MRI has the potential to investigate both the biological and the structural character of tissues. It has great potential in the assessment of the functional status of different organs, in the differentiation between benign and malignant lesions, in the monitoring of various treatment strategies and even in the prediction of outcome. However, a strong collaboration among radiologists, physicists and clinicians is the prerequisite for a successful extracranial application of DW-MRI.

Acknowledgment We would like to thank Dr. Anwar R. Padhani of the Mount Vernon Cancer Centre, London, for his many helpful comments on this manuscript.

\section{References}

1. Carr HY, Purcell EM (1954) Effects of diffusion on free precession in nuclear magnetic resonance experiments. Phys Rev 94:630-638

2. Hahn EL (1950) Spin echoes. Phys Rev 80:580-594

3. Stejskal EO, Tanner JE (1965) Spin diffusion measurements: spin echoes in the presence of a time-dependent field gradient. J Chem Phys 42:288-292

4. Moseley ME, Cohen Y, Mintorovitch J, Chileuitt L, Shimizu H, Kucharczyk J, Wendland MF, Weinstein PR (1990) Early detection of regional cerebral ischemia in cats: comparison of diffusion- and T2-weighted MRI and spectroscopy. Magn Reson Med 14:330-346

5. Le Bihan D, Breton E, Lallemand D, Aubin ML, Vignaud J, Laval-Jeantet M (1988) Separation of diffusion and perfusion in intravoxel incoherent motion MR imaging. Radiology 168:497-505

6. Neil JJ, Ackerman JH (1992) Detection of pseudodiffusion in rat brain following blood substitution wth perfluorocarbon. J Magn Reson 97:194-201

7. Schaefer PW, Grant PE, Gonzalez RG (2000) Diffusion-weighted MR imaging of the brain. Radiology 217:331-345

8. Murtz P, Flacke S, Traber F, van den Brink JS, Gieseke J, Schild HH (2002) Abdomen: diffusion-weighted MR imaging with pulse-triggered single-shot sequences. Radiology 224:258-264

9. Thoeny HC, De Keyzer F, Boesch C, Hermans R (2004) Diffusion-weighted imaging of the parotid gland: influence of the choice of b-values on the apparent diffusion coefficient value. J Magn Reson Imaging 20:786-790
10. Mardor Y, Pfeffer R, Spiegelmann R, Roth Y, Maier SE, Nissim O, Berger R, Glicksman A, Baram J, Orenstein A, Cohen JS, Tichler T (2003) Early detection of response to radiation therapy in patients with brain malignancies using conventional and high b-value diffusion-weighted magnetic resonance imaging. J Clin Oncol 21:1094-1100

11. Lyng H, Haraldseth O, Rofstad EK (2000) Measurement of cell density and necrotic fraction in human melanoma xenografts by diffusion weighted magnetic resonance imaging. Magn Reson Med 43:828-836

12. Bammer R (2003) Basic principles of diffusion-weighted imaging. Eur J Radiol 45:169-184

13. Ries M, Jones RA, Basseau F, Moonen CT, Grenier N (2001) Diffusion tensor MRI of the human kidney. J Magn Reson Imaging 14:42-49

14. Muller MF, Prasad P, Siewert B, Nissenbaum MA, Raptopoulos V, Edelman RR (1994) Abdominal diffusion mapping with use of a whole-body echo-planar system. Radiology 190:475-478

15. Siegel CL, Aisen AM, Ellis JH, Londy F, Chenevert TL (1995) Feasibility of MR diffusion studies in the kidney. J Magn Reson Imaging 5:617-620

16. Yamada I, Aung W, Himeno Y, Nakagawa T, Shibuya H (1999) Diffusion coefficients in abdominal organs and hepatic lesions: evaluation with intravoxel incoherent motion echo-planar MR imaging. Radiology 210:617-623

17. Jones RA, Grattan-Smith JD (2003) Age dependence of the renal apparent diffusion coefficient in children. Pediatr Radiol 33:850-854

18. Prasad PV, Priatna A (1999) Functional imaging of the kidneys with fast MRI techniques. Eur J Radiol 29:133-148

19. Namimoto T, Yamashita Y, Mitsuzaki K, Nakayama Y, Tang Y, Takashani M (1999) Measurement of the apparent diffusion coefficient in diffuse renal disease by diffusion-weighted echoplanar MR imaging. J Magn Reson Imaging 9:832-837
20. Chow LC, Bammer R, Moseley ME, Sommer FG (2003) Single breath-hold diffusion-weighted imaging of the abdomen. J Magn Reson Imaging 18:377-382

21. Yang D, Ye Q, Williams DS, Hitchens TK, Ho C (2004) Normal and transplanted rat kidneys: diffusion MR imaging at 7T. Radiology 231:702-709

22. Thoeny HC, De Keyzer F, Oyen RH, Peeters RR (2005) Diffusion-weighted MR imaging of kidneys in healthy volunteers and patients with parenchymal diseases: initial experience. Radiology 235:911-917

23. Ichikawa T, Haradome H, Hachiya J, Nitatori T, Araki T (1999) Diffusionweighted MR imaging with single-shot echo-planar imaging in the upper abdomen: preliminary clinical experience in 61 patients. Abdom Imaging 24:456-461

24. Muller MF, Prasad PV, Bimmler D, Kaiser A, Edelman RR (1994) Functional imaging of the kidney by means of measurement of the apparent diffusion coefficient. Radiology 193:711715

25. Pedersen M, Wen JG, Shi Y, Beigi N, Christensen TB, Stodkilde-Jorgensen H, Frokiaer J (2003) The effect of unilateral ureteral obstruction on renal function in pigs measured by diffusionweighted MRI. APMIS Suppl 109:2934

26. Ries M, Basseau F, Tyndal B, Jones R, Deminiere C, Catargi B, Combe C, Moonen CW, Grenier N (2003) Renal diffusion and BOLD MRI in experimental diabetic nephropathy. J Magn Reson Imaging 17:104-113 
27. Liu AS, Xie JX (2003) Functional evaluation of normothermic ischemia and reperfusion injury in dog kidney by combining MR diffusion-weighted imaging and Gd-DTPA enhanced firstpass perfusion. J Magn Reson Imaging 17:683-693

28. Fukuda Y, Ohashi I, Hanafusa K, Nakagawa T, Ohtani S, An-naka Y, Hayashi T, Shibuya H (2000) Anisotropic diffusion in kidney: apparent diffusion coefficient measurements for clinical use. J Magn Reson Imaging $11: 156-160$

29. Chan JH, Tsui EY, Luk SH, Fung SL, Cheung YK, Chan MS, Yuen MK, Mak SF, Wong KP (2001) MR diffusionweighted imaging of kidney: differentiation between hydronephrosis and pyonephrosis. Clin Imaging 25:110 113

30. Toyoshima S, Noguchi K, Seto H, Shimizu M, Watanabe N (2000) Functional evaluation of hydronephrosis by diffusion-weighted MR imaging. Relationship between apparent diffusion coefficient and split glomerular filtration rate. Acta Radiol 41:642-646

31. Squillaci E, Manenti G, Di Stefano F, Miano R, Strigari L, Simonetti G (2004) Diffusion-weighted MR imaging in the evaluation of renal tumours. J Exp Clin Cancer Res 23:39-45

32. Sumi M, Takagi Y, Uetani $M$,

Morikawa M, Hayashi K, Kabasawa H, Aikawa K, Nakamura T (2002) Diffusion-weighted echoplanar MR imaging of the salivary glands. AJR Am J Roentgenol 178:959-965

33. Yoshino N, Yamada I, Ohbayashi N, Honda E, Ida M, Kurabayashi T, Maruyama K, Sasaki T (2001) Salivary glands and lesions: evaluation of apparent diffusion coefficients with split-echo diffusion-weighted MR imaging-initial results. Radiology 221:837-842

34. Zhang L, Murata Y, Ishida R, Ohashi I, Yoshimura R, Shibuya H (2001) Function evaluation with intravoxel incoherent motion echo-planar MRI in irradiated salivary glands: a correlative study with salivary gland scintigraphy. J Magn Reson Imaging 14:223-229

35. Thoeny HC, De Keyzer F, Claus FG, Sunaert S, Hermans R (2005) Gustatory stimulation changes the apparent diffusion coefficient of salivary glands. Radiology 235:629-634
36. Habermann CR, Cramer MC, Graessner J, Gossrau P, Reitmeier F, Fiehler J, Schoder V, Jaehne M, Adam G (2004) Functional imaging of parotid glands: diffusion-weighted echo-planar MRI before and after stimulation. Rofo 176:1385-1389

37. Habermann CR, Gossrau P, Graessner J, Arndt C, Cramer MC, Reitmeier F, Jaehne M, Adam G (2005) Diffusionweighted echo-planar MRI: a valuable tool for differentiating primary parotid gland tumors? RoFo 177:940-945

38. Erturk SM, Ichikawa T, Motosugi U, Sou H, Araki T (2006) Diffusionweighted MR imaging in the evaluation of pancreatic exocrine function before and after secretin stimulation. Am J Gastroenterol 101:133-136

39. Lang P, Wendland MF, Saeed M, Gindele A, Rosenau W, Mathur A, Gooding CA, Genant HK (1998) Osteogenic sarcoma: noninvasive in vivo assessment of tumor necrosis with diffusion-weighted MR imaging. Radiology 206:227-235

40. Gupta RK, Cloughesy TF, Sinha U, Garakian J, Lazareff J, Rubino G, Rubino L, Becker DP, Vinters HV, Alger JR (2000) Relationships between choline magnetic resonance spectroscopy, apparent diffusion coefficient and quantitative histopathology in human glioma. J Neurooncol 50:215-226

41. Sugahara T, Korogi Y, Kochi M, Ikushima I, Shigematu Y, Hirai T, Okuda T, Liang L, Ge Y, Komohara Y, Ushio Y, Takahashi M (1999) Usefulness of diffusion-weighted MRI with echo-planar technique in the evaluation of cellularity in gliomas. J Magn Reson Imaging 9:53-60, 1999

42. Uhl M, Altehoefer C, Kontny U, Il'yasov K, Büchert M, Langer M (2002) MRI-diffusion imaging of neuroblastomas: first results and correlation with histology. Eur Radiol 12:2335-2338

43. Kim T, Murakami T, Takahashi S, Hori M, Tsuda K, Nakamura H (1999) Diffusion-weighted single-shot echoplanar MR imaging for liver disease. AJR Am J Roentgenol 173:393-398

44. Issa B (2002) In vivo measurement of the apparent diffusion coefficient in normal and malignant prostatic tissues using echo-planar imaging. J Magn Reson Imaging 16:196-200

45. Wheeler-Kingshott CA, Thomas DL, Lythgoe MF, Guilfoyle D, Williams SR, Doran SJ (2000) Burst excitation for quantitative diffusion imaging with multiple b-values. Magn Reson Med 44:737-745
46. Koinuma M, Ohashi I, Hanafusa K, Shibuya H (2005) Apparent diffusion coefficient measurements with diffusion-weighted magnetic resonance imaging for evaluation of hepatic fibrosis. J Magn Reson Imaging 22:80-85

47. Taouli B, Vilgrain V, Dumont E, Daire JL, Fan B, Menu Y (2003) Evaluation of liver diffusion isotropy and characterization of focal hepatic lesions with two single-shot echo-planar MR imaging sequences: prospective study in 66 patients. Radiology 226:71-78

48. Naganawa S, Sato C, Nakamura T, Kumada H, Ishigaki T, Miura S, Maruyama K, Takizawa O (2005) Diffusion-weighted images of the liver: comparison of tumor detection before and after contrast enhancement with superparamagnetic iron oxide. J Magn Reson Imaging 21:836-840

49. Sinha S, Lucas-Quesada FA, Sinha U, DeBruhl N, Bassett LW (2002) In vivo diffusion-weighted MRI of the breast: potential for lesion characterization. $\mathrm{J}$ Magn Reson Imaging 15:693-704

50. Guo Y, Cai YQ, Cai ZL, Gao YG, An NY, Ma L, Mahankali S, Gao JH (2002) Differentiation of clinically benign and malignant breast lesions using diffusion-weighted imaging. J Magn Reson Imaging 16:172-178

51. Woodhams R, Matsunaga K, Iwabuchi K, Kan S, Hata H, Kuranami M, Watanabe M, Hayakawa K (2005) Diffusion-weighted imaging of malignant breast tumors: the usefulness of apparent diffusion coefficient (ADC) value and $\mathrm{ADC}$ map for the detection of malignant breast tumors and evaluation of cancer extension. J Comput Assist Tomogr 29:644-649

52. Sumi M, Sakihama N, Sumi T, Morikawa M, Uetani M, Kabasawa H, Shigeno K, Hayashi K, Takahashi H, Nakamura T (2003) Discrimination of metastatic cervical lymph nodes with diffusion-weighted MR imaging in patients with head and neck cancer. AJNR Am J Neuroradiol 24:1627-1634

53. Dubrulle F, Souillard R, Chechin D, Vaneecloo FM, Desaulty A, Vincent C (2006) Diffusion-weighted MR imaging sequence in the detection of postoperative recurrent cholesteatoma. Radiology 238:604-610 
54. Vercruysse JP, De Foer B, Pouillon M, Somers T, Casselman J, Offeciers E (2006) The value of diffusion-weighted MR imaging in the diagnosis of primary acquired and residual cholesteatoma: a surgical verified study of 100 patients. Eur Radiol 16(7):1461-1467

55. Stasolla A, Magliulo G, Parrotto D, Luppi G, Marini M (2004) Detection of postoperative relapsing/residual cholesteatomas with diffusion-weighted echo-planar magnetic resonance imaging. Otol Neurotol 25:879-884

56. Stasolla A, Magliulo G, Lo Mele L, Prossomariti G, Luppi G, Marini M (2004) Value of echo-planar diffusionweighted MRI in the detection of secondary and postoperative relapsing/ residual cholesteatoma. Radiol Med (Torino) 107:556-568

57. Aikele P, Kittner T, Offergeld C, Kaftan H, Huttenbrink KB, Laniado M (2003) Diffusion-weighted MR imaging of cholesteatoma in pediatric and adult patients who have undergone middle ear surgery. AJR Am J Roentgenol 181:261-265

58. Herneth AM, Philipp MO, Naude J, Funovics M, Beichel RR, Bammer R, Imhof H (2002) Vertebral metastases: assessment with apparent diffusion coefficient. Radiology 225:889-894

59. Park SW, Lee JH, Ehara S, Park YB, Sung SO, Choi JA, Joo YE (2004) Single shot fast spin echo diffusionweighted MR imaging of the spine; is it useful in differentiating malignant metastatic tumor infiltration from benign fracture edema? Clin Imaging 28:102-108

60. Baur A, Stabler A, Bruning R, Bartl R, Krodel A, Reiser M, Deimling M (1998) Diffusion-weighted MR imaging of bone marrow: differentiation of benign versus pathologic compression fractures. Radiology 207:349-356

61. Chan JH, Peh WC, Tsui EY, Chau LF, Cheung KK, Chan KB, Yuen MK, Wong ET, Wong KP (2002) Acute vertebral body compression fractures: discrimination between bening and malignant causes using apparent diffusion coefficients. Br J Radiol 75:207-214
62. Baur A, Huber A, Ertl-Wagner B, Durr R, Zysk S, Arbogast S, Deimling M, Reiser M (2001) Diagnostic value of increased diffusion weighting of a steady-state free precession sequence for differentiating acute bening osteoporotic fractures from pathologic vertebral compression fractures. AJNR Am J Neuroradiol 22:366-372

63. Byun WM, Shin SO, Chang Y, Lee SJ, Finsterbusch J, Frahm J (2002) Diffusion-weighted MR imaging of metastatic disease of the spine: assessment of response to therapy. AJNR Am J Neuroradiol 23:906-912

64. van Rijswijk CS, Kunz P, Hogendoorn $\mathrm{PC}$, Taminiau AH, Doornbos J, Bloem JL (2002) Diffusion-weighted MRI in the characterization of soft-tissue tumors. J Magn Reson Imaging 15:302307

65. Einarsdottir H, Karlsson M, Wejde J, Bauer HC (2004) Diffusion-weighted MRI of soft tissue tumours. Eur Radiol 14:959-963

66. Katayama M, Masui T, Kobayashi S, Ito T, Sakahara H, Nozaki A, Kabasawa H (2002) Diffusion-weighted echo planar imaging of ovarian tumors: is it useful to measure apparent diffusion coefficients? J Comput Assist Tomogr 26:250-256

67. Nakayama T, Yoshimitsu K, Irie H, Aibe H, Tajima T, Nishie A, Asayama Y, Matake K, Kakihara D, Matsuura S, Nakano H, Honda H (2005) Diffusionweighted echo-planar MR imaging and ADC mapping in the differential diagnosis of ovarian cystic masses: usefulness of detecting keratinoid substances in mature cystic teratomas. J Magn Reson Imaging 22:271-278

68. Shimofusa R, Fujimoto H, Akamata $H$, Motoori K, Yamamoto S, Ueda T, Ito H (2005) Diffusion-weighted imaging of prostate cancer. J Comput Assist Tomogr 29:149-153

69. Hosseinzadeh K, Schwarz SD (2004) Endorectal diffusion-weighted imaging in prostate cancer to differentiate malignant and benign peripheral zone tissue. J Magn Reson Imaging 20:654661

70. Pickles MD, Gibbs P, Sreenivas M, Turnbull LW (2006) Diffusionweighted imaging of normal and malignant prostate tissue at 3.0T. J Magn Reson Imaging 23:130-134
71. Dzik-Jurasz A, Domenig C, George M, Wolber J, Padhani A, Brown G, Doran S (2002) Diffusion MRI for prediction of response of rectal cancer to chemoradiation. Lancet 360:307-308

72. DeVries AF, Kremser C, Hein PA, Griebel J, Krezcy A, Ofner D, Pfeiffer KP, Lukas P, Judmaier W (2003) Tumor microcirculation and diffusion predict therapy outcome for primary rectal carcinoma. Int J Radiat Oncol Biol Phys 56:958-965

73. Thoeny HC, De Keyzer F, Chen F, Ni Y, Landuyt W, Verbeken EK, Bosmans H, Marchal G, Hermans R (2005) Diffusion-weighted MR imaging in monitoring the effect of a vascular targeting agent on rhabdomyosarcoma in rats. Radiology 234:756-764

74. Chenevert TL, Stegman LD, Taylor JM, Robertson PL, Greenberg HS, Rehemtulla A, Ross BD (2000) Diffusion magnetic resonance imaging: an early surrogate marker of therapeutic efficacy in brain tumors. J Natl Cancer Inst 92:2029-2035

75. Galons JP, Altbach MI, Paine-Murrieta GD, Taylor CW, Gillies RJ (1999) Early increases in breast tumor xenograft water mobility in response to paclitaxel therapy detected by noninvasive diffusion magnetic resonance imaging. Neoplasia 1:113-117

76. Thoeny HC, De Keyzer F, Vandecaveye V, Chen F, Sun X, Bosmans H, Hermans R, Verbeken EK, Boesch C, Marchal G, Landuyt W, Ni Y (2005) Effect of vascular targeting agent in rat tumor model: dynamic contrast-enhanced versus diffusionweighted MR imaging. Radiology 237:492-499

77. Jacobs MA, Herskovits EH, Kim HS (2005) Uterine fibroids: diffusionweighted MR imaging for monitoring therapy with focused ultrasound surgery-preliminary study. Radiology 236:196-203

78. Kamel IR, Bluemke DA, Ramsey D, Abusedera M, Torbenson M, Eng J, Szarf G, Geschwind JF (2003) Role of diffusion-weighted imaging in estimating tumor necrosis after chemoembolization of hepatocellular carcinoma. AJR Am J Roentgenol 181:708-710 